\title{
BPM35
}

\section{D Petroleum Systems Model using Restored Paleo-Geometries}

\author{
C. Castagnac (Schlumberger), E. Mavridou* (Schlumberger), G. Badalini \\ (BG), M. Moktar Mohamed (Rashpetco), S. Ahmed Mousa (Rashpetco), J. \\ McQuilken (BG) \& A. Yehya El Amir (Rashpetco)
}

\section{SUMMARY}

3D petroleum systems modeling is an integrated approach that includes thermogenic source rock maturation, hydrocarbon generation timing, migration and trap formation (Hantschel and Kauerauf, 2009). Evaluating the key elements during the charge and trap forming processes is of fundamental importance when assessing the risk of a working petroleum system.

Parameters which affect the petroleum system, such as source rock properties, trap system, and migration flow path through carrier rocks and fault geometries directly depend on the tectonic history of the basin. Therefore, addressing the structural evolution of the petroleum system's geometry and using appropriate paleo-geometries is a key requirement to be able to adequately evaluate the risks.

There are two ways to address the forward modeling: backstripping and paleo-reconstruction. The backstripping approach is a vertical shifting process in which a model is recompacted layer by layer. With paleo-reconstruction, a model is described by paleo-sections based on geomechanical restoration. 


\section{Introduction}

3D petroleum systems modeling is an integrated approach that includes thermogenic source rock maturation, hydrocarbon generation timing, migration and trap formation (Hantschel and Kauerauf, 2009).

Evaluating the key elements during the charge and trap forming processes is of fundamental importance when assessing the risk of a working petroleum system.

Parameters which affect the petroleum system, such as source rock properties, trap system, and migration flow path through carrier rocks and fault geometries directly depend on the tectonic history of the basin. Therefore, addressing the structural evolution of the petroleum system's geometry and using appropriate paleo-geometries is a key requirement to be able to adequately evaluate the risks.

There are two ways to address the forward modeling: backstripping and paleo-reconstruction. The backstripping approach is a vertical shifting process in which a model is recompacted layer by layer. With paleo-reconstruction, a model is described by paleo-sections based on geomechanical restoration.

\section{Method and Results}

The study area of this project was located in a deep water listric growth fault system and the 3D petroleum systems model was built covering an area of $130 * 90 \mathrm{~km}$ and is $8 \mathrm{~km}$ deep.

The workflow comprises of three main steps: thermal and pressure calibration, reconstruction of the paleo-geometries, and the construction and migration simulation of the structurally reconstructed petroleum systems model.

1/ Thermal and pressure calibration

Present day geometries, source rock properties and the depositional environment were used to build the master model (standard backstripping model based only on present day geometries). Vitrinite reflectance, wellbore temperature and porosity were used to calibrate the master model.

2/ Geomechanical reconstruction of paleo-geometries

A $3 \mathrm{D}$ restoration was then performed with the strain-based decompaction technology using geomechanical properties of the assigned lithologies. This allows sliding movement along faults for a more realistic layer geometry and thickness variation (Maerten and Maerten, 2006).

3/ Construction of the structurally reconstructed petroleum systems model and migration simulation The paleo-models from the reconstruction were incorporated in the master model with a fault displacement analysis to infer hydrocarbon flow paths through time. Additionally, a sensitivity analysis was performed to define the key uncertainty parameters.

The simulation results indicate that at present day, for the deepest parts of the source rock, there is a $100 \%$ conversion of kerogen to hydrocarbons. Figure 1 shows the transformation of kerogen to petroleum, in percentage, for the different paleo-sections. 


\section{EAGE}
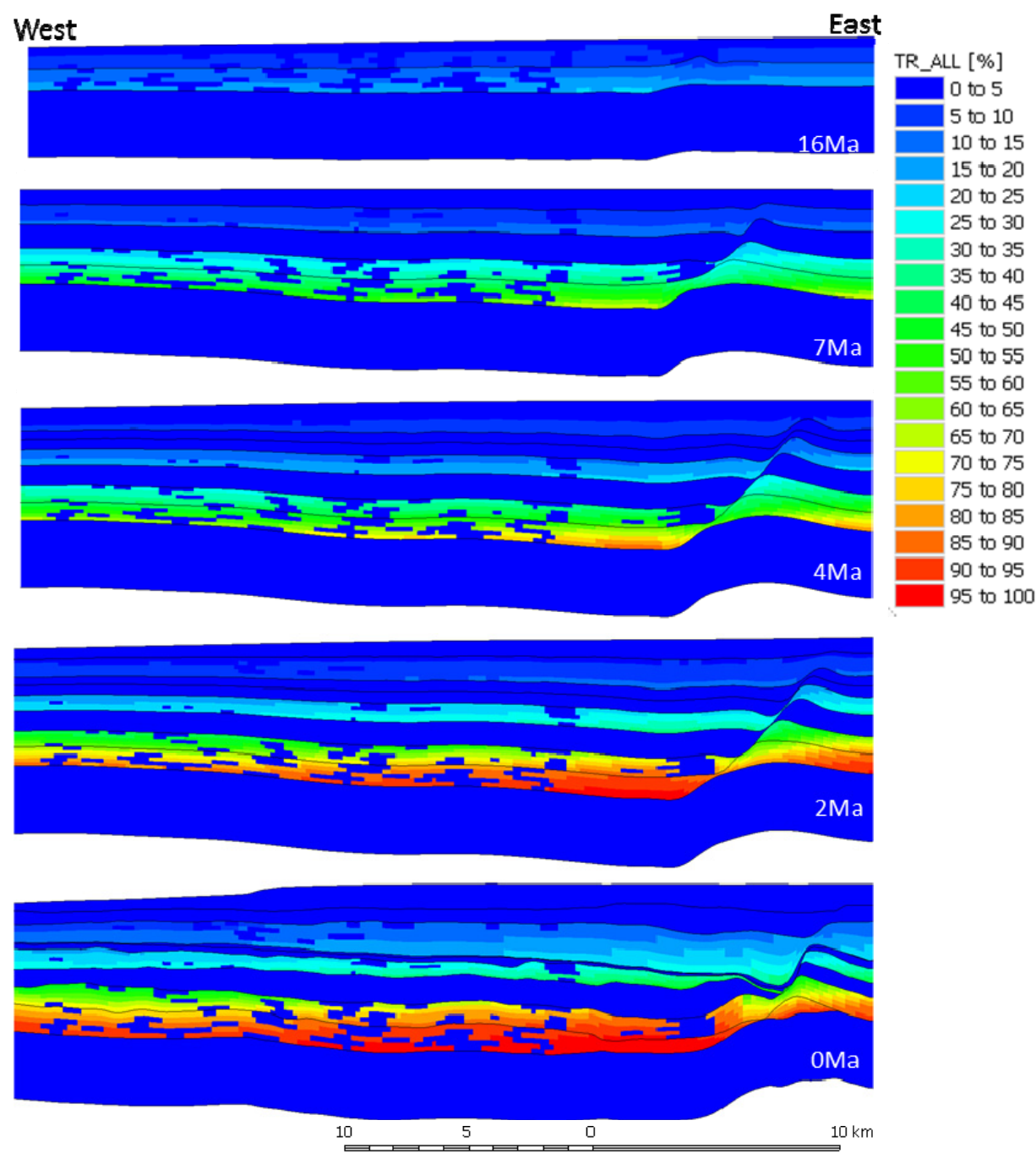

Figure $12 D$ extractions from the $3 D$ petroleum systems model, displaying the evolution of source rock maturation at different paleo-time steps (TR_ALL: transformation ratio).

\section{Conclusion}

Because the study area is subjected to various tectonic events, using a paleo reconstruction preserved the coherent evolution of basin geometries, controlled the fault activity through time and proved the existence of hydrocarbon accumulations prior to a drilling phase.

Combining the simulation results with an uncertainties evaluation of the reservoir, charge and trap is of fundamental importance to assess the main risks of a working petroleum system.

\section{References}

Hantschel, T. and Kauerauf, A.I. [2009] Fundamentals of Basin and Petroleum Systems Modeling. Springer-Verlag, 476.

Maerten, L. and Maerten, F. [2006] Chronologique modeling of faulted and fractured reservoirs using geomechanically based restoration: Technique and industry applications. American Association of Petroleum Geologist Bulletin, 90, 1201-1226. 